\title{
Epidural hematoma in newborn: literature review
}

\author{
Isabela do Prado Nascimento', Gabriela Ferreira Kalkmann', Leticia Adrielle dos Santos², \\ Letícia Novak Crestani ${ }^{3}$, Carlos Umberto Pereira ${ }^{4}$
}

Received: 27 June 2020 / Published: 16 September 2020

\begin{abstract}
Introduction: Newborn represent a population at high risk for brain damage. Intracranial hemorrhages in newborn are uncommon, and epidural hematoma $(\mathrm{EH})$ is rare.

Material and methods: The authors present a literature review about $\mathrm{EH}$ in newborn.

Results: EH in newborn occurs in only $2 \%$ and is frequently associated with the type of delivery. The clinical presentation is asymptomatic or heterogeneous. The diagnosis is made from anamnesis and imaging exams, and the treatment depends on the size of the $\mathrm{EH}$.

Conclusion: The knowledge of neurosurgeons, obstetricians and pediatricians about the occurrence of $\mathrm{EH}$ in newborn is extremely important. The rapid identification and management of the case is of paramount importance, to reduce neurological sequelae.
\end{abstract}

Key words: Cranial Epidural Hematoma; Neuroimaging; Newborn.

\footnotetext{
${ }^{1}$ Federal University of Paraná, Curitiba, Brasil.

${ }^{2}$ Federal University of Sergipe, Aracaju, Brasil.Brazil

${ }^{3}$ Medicine Faculty of the Maringá University Center, Maringá, Brasil.

${ }^{4}$ Departament of Neurosurgery, Sergipe Emergency Hospital. Preceptor of the Neurosurgery Residency at Surgery Hospital Charitable Foundation, Aracaju, Brasil
}

To whom correspondence should be addressed: Carlos Umberto Pereira, MD, PhD [E-mail: umberto@infonet.com.br]

\section{Introduction}

Epidural hematoma (EH) consists of the accumulation of blood between the dura and the skull [1], due to a traumatic brain injury (TBI) at any age, however, it infrequently occurs in newborn $[2,3,5,6,7,8,9,10,11,12]$, with an incidence of $0.06 \%$ to $2 \%$ in this population [13]. They are due to birth injury $[7,11,14,15,16,17,18,19]$, accidental fall, traffic accident, mistreatment and alterations in blood clotting. Usually associated with cephalohematomas, trauma and/or fracture of the temporal region due to rupture of the middle meningeal artery (MMA), however, the MMA is not fully adhered to in newborn skullcap, the small venous vessels and the meningeal artery are often the source for the formation of $\mathrm{EH}$ [20].

Newborn represent a high-risk population for clinically important brain injuries [21]. Newborn intracranial hemorrhage is uncommon [22], $\mathrm{EH}$ is rare in this period, and the most common cause being labor [23].

\section{Method}

The authors present a literature review using the following bases: PubMed, Google Scholar, Lilacs, Scielo, TripDataBase, Sciencedirect using the terms: "epidural hematoma" AND "newborn", and "extradural hematoma" AND "newborn". Articles in the period from 1951 to 2018 were selected, resulting in a total of 162 articles related to intracranial $\mathrm{EH}$ in newborn, withdrawal of duplicate papers, and in the languages english, portuguese, spanish and french (Figure 1, tables 1 and 2). And, 2 book chapters and 11 papers were selected without this method due to the correspondence found with the theme. 


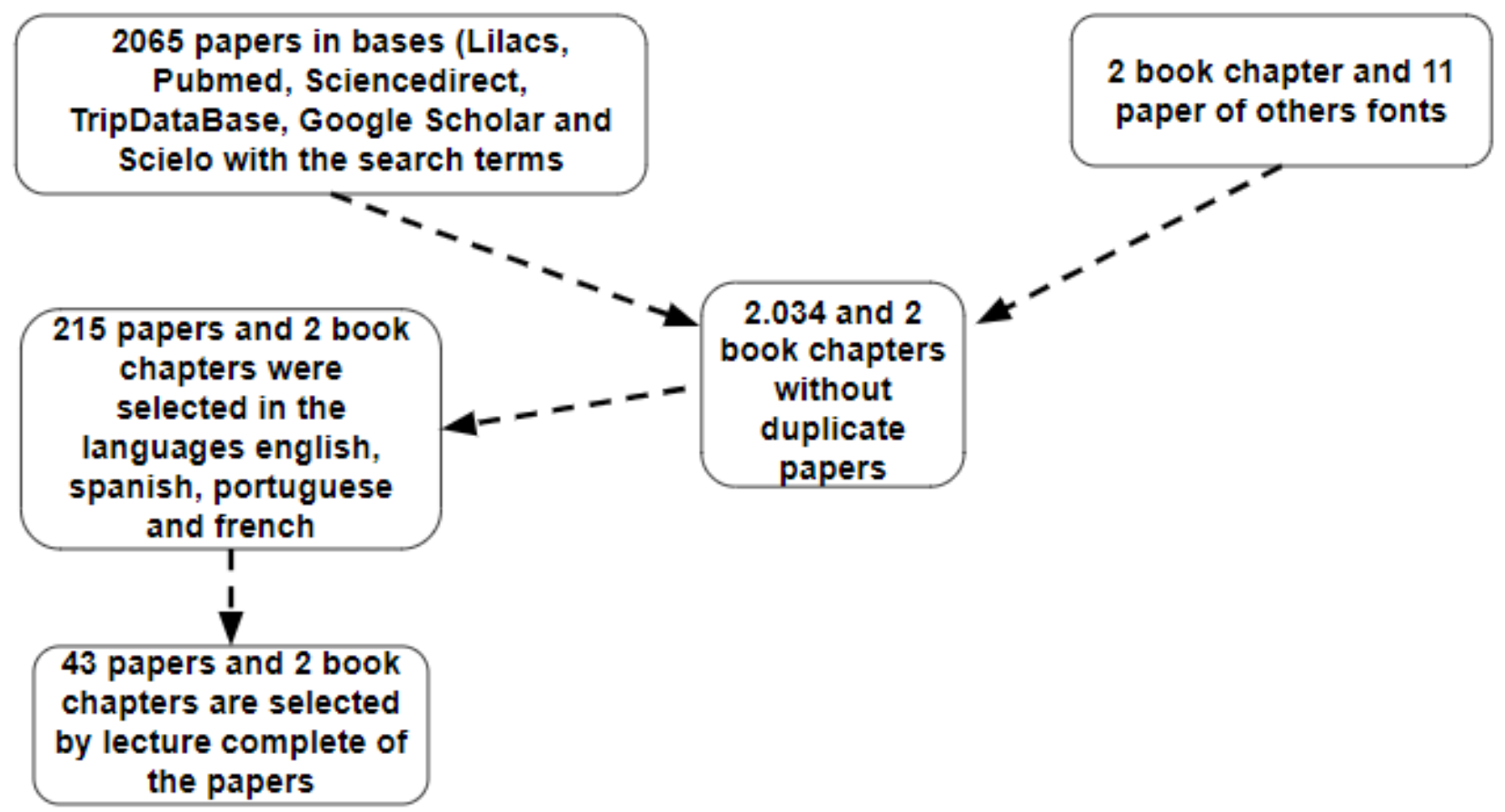

Figure 1. Flowchart of the literature systematic review

Table 1. Results with the term "Epidural Hematoma" AND "Newborn"

\begin{tabular}{cccc}
\multicolumn{4}{c}{ "Epidural Hematoma" AND "newborn" } \\
\hline Plataform & $\begin{array}{c}\text { Results } \\
\text { (Articles) } \\
\text { (English, } \\
\text { Portuguese, } \\
\text { Spanish, } \\
\text { French) }\end{array}$ & $\begin{array}{c}\text { Final Results } \\
\text { (Related } \\
\text { Assunt) }\end{array}$ \\
\hline PubMed & 192 & 162 & 46 \\
Google Scholar & 980 & 945 & 54 \\
Scielo & 2 & - & 1 \\
TripDataBase & 76 & - & 1 \\
Sciencedirect & 518 & 517 & 13 \\
LILACS & 1 & - & 0 \\
Cochrane & 1 & - & 0 \\
\hline Articles Total & 1770 & 1624 & 111 \\
\hline
\end{tabular}

Table 2. Results with the term "Extradural Hematoma" AND "Newborn"

"Extradural Hematoma" AND "newborn"

\begin{tabular}{cccc}
\hline Plataform & $\begin{array}{c}\text { Results } \\
\text { (Articles) }\end{array}$ & $\begin{array}{c}\text { Results } \\
\text { (English, } \\
\text { Portuguese, } \\
\text { Spanish, } \\
\text { French) }\end{array}$ & $\begin{array}{c}\text { Final Results } \\
\text { (Related } \\
\text { Assunt) }\end{array}$ \\
\hline PubMed & 20 & - & 11 \\
Google Scholar & 306 & 295 & 68 \\
TripDataBase & 13 & - & 1 \\
Sciencedirect & 90 & - & 12 \\
LILACS & 2 & - & 1 \\
\hline Articles Total & 431 & 295 & 93 \\
\hline
\end{tabular}

\section{Results}

\section{Epidemiology and causes}

Intracranial injuries sustained during delivery are rare but significant causes of neonatal morbidity and mortality [24]. The injury that occurs during birth is divided into two categories: injuries produced by the normal force of labor, and the second group, due to obstetric intervention [19]. The most frequent causes are mechanical assistance during delivery, such as the use of forceps and vacuum extraction, precipitated delivery and TBI after delivery [12]. Falls are the most common cause of unintentional injuries in children 0-3 months of age [25]. The neonates with the highest risk group for head trauma are male, born at term to primiparous mothers, with difficult births due to cephalopelvic disproportion or abnormal presentation [14].

Pollina et al [26] described the following traumatic intracranial injuries due to birth injury: subdural hemorrhage $(73 \%)$, subarachnoid hemorrhage $(20 \%)$, intracerebral hemorrhage (20\%), intraventricular hemorrhage and $\mathrm{EH}$, the latter two are less frequent. $\mathrm{EH}$ occurs in $2 \%$ of all cranioencephalic hemorrhages in this population [1]. In neonates, there are less than 80 reported cases, often associated with the type of delivery and accidental falls, and for this reason it is considered a rare event [27]. Spontaneous subdural or cerebral hemorrhage occurs in 2.9 out of 10,000 vaginal deliveries, increasing to 21.3 when vacuum or forceps are used [23]. 


\section{EH \\ Neonatal cranial anatomy and pathophysiology of}

The skull of newborn is soft, deformable, elastic and its sutures are not consolidated; associated with the presence of fontanelles, allows cranial deformation without the occurrence of bone fracture $[4,8,10]$. Laceration of the dura mater and blood vessels is rare, due to the adhesion of the meninges to the skullcap internal bone plate, mainly at the level of the sutures, especially in the coronal suture; this adhesion, however, is reduced in the center of the skull $[7,10,28]$.

The rarity of $\mathrm{EH}$ in newborn compared to children or adults is explained by the absence of the cranial sulcus of MMA, making the latter less susceptible to injuries [29], since in older children and young adults arterial rupture is frequently observed in TBI [10]. The preferred location of $\mathrm{EH}$ is in the temporoparietal region, being rare in frontal region, due to the adhesion of the dura mater in the membranous portion of the coronal suture, being more infrequent in the posterior fossa $[30,31,32]$, and commonly occurring unilaterally [32]. In newborn, MMA is not fixed in grooves in the skull, freely moving between the dura and the skull, so $\mathrm{EH}$ is often constituted by bleeding from ruptured dural sinuses [14], such as the superior sagittal sinus, confluence of the sinuses and transverse sinuses [11], however, in some cases the source of the bleeding is unknown. The vascular richness of cranial bones, as well as the dura mater in newborn, is more pronounced in relation to older children, explaining the higher frequency of $\mathrm{EH}$ in lactating and younger children. The time of $\mathrm{EH}$ formation in neonates is ambiguous and does not have an established period [22], since the size of the hematoma and the speed formation depend on the length of the dura detached in the internal cranial bone plate and affected vessel caliber.

One of the bleeding mechanisms is local stress due to excessive molding or contusions during delivery, such as the use of forceps or vacuum fetal extraction, causing the dura to detach from the skullcap internal surface, with consequent destruction of the vascular connection between the skull and the internal periosteum [2,33]. During vaginal deliveries, significant changes in fetal cephalic geometry occur, such as the overlap between the frontal and parietal bones. Bleeding from the bridging brain veins and the Galen vein at the junction with the rectal sinus can lead to intracranial hemorrhage. Therefore, a rapid delivery can accelerate the changes in the head of the newborn, developing intracranial hemorrhage [24]. The proposed mechanism for this form of $\mathrm{EH}$ development is due to the pressure of the pregnant ischial tuberosity on the newborn skull, resulting in flexion of the fetus head [19].

\section{Symptomatology}

The patient may be asymptomatic or present with heterogeneous symptoms [34]. The latter, when present, includes: muscle hypotonia, apnea, seizures, macrocephaly, bulging of the anterior fontanelle, anemia, bradycardia [7,35], irritability and persistent crying [34]. Anemia associated with pallor is an important finding in neonates with $\mathrm{EH}[10,32,36,37]$. The occurrence of focal neurological symptoms is relatively delayed in relation to the $\mathrm{EH}$ formation event [29]. The presence of anisocoria and contralateral motor deficit are rare in neonates [7]. Due to the good tolerance to the presence of $\mathrm{EH}$ presented by the newborn, a long lucid interval is observed in relation to older children and young adults, since the open fontanelles and the non-consolidation of the sutures allow the compensation of the elevated intracranial pressure, often associated with intracranial hematoma $[7,10]$. Convulsive seizures and muscle hypotonia are commonly associated with neonates with EH [8]. Depending of the trauma intensity, the presence of cerebral contusion, intracerebral hemorrhage, subdural hematoma and cerebral edema may occur simultaneously with $\mathrm{EH}$. Calcification or ossification of $\mathrm{EH}$ in neonates is rare, and often results from the excessive production of repair tissue, synthesized after trauma $[28,38,39,40,41]$.

\section{Diagnosis}

The diagnosis is made in association with imaging tests, and anamnesis with legal guardians. A simple skull radiograph shows a linear fracture trace in about $70 \%$ of the cases, however, its absence does not eliminate the presence of EH $[8,29]$. The CT is the gold standard diagnostic tool, which is a simple, fast and efficient method for diagnosis accuracy, presenting the presence of the clot, location, size, shape, associated lesions, assisting in therapeutic planning and post-operative follow-up $[27,42,43]$. The CT indications in newborn suspected of intracranial hemorrhage are: seizures with normal serum biochemistry (hypoglycemia or hypocalcemia), seizures with hemorrhagic problems in neonates, lethargy and progressive neurological deterioration [19].

The $\mathrm{EH}$ on CT shows high density, not differentiating from other age groups [22]. However, $\mathrm{EH}$ has a rounded and circumscribed shape as a clinical feature, due to the anatomical limitation of the intimate relationship between meninges, periosteum and cranial sutures [24], so blood accumulates in this space due to the dripping of ruptured vessels [21]. Cephalohematoma is frequently found in communicating EH with skull fracture [21], being found in $16 \%$ to $75 \%$ of cases $[8,12,13,22,26,29,44]$.

There are reports on the use of transfontanellar ultrasound and magnetic resonance imaging as a means of confirming the diagnosis because they do not expose the patient to radiation [33], since they are sensitive to the adverse effects of ionizing radiation [21]. 


\section{Treatment}

The therapeutic attitude faces variables that can modify the treatment, such as symptoms, progression of the case and the size of the epidural collection. In most cases, $\mathrm{EH}$ is well delimited and has small volume, not requiring surgical intervention, associated with spontaneous resolution, performing only neurological surveillance associated with CT scan $[8,13,19,29,34]$, in case of deterioration of the level of consciousness or increase in volume of the lesion, the surgical intervention is indicated. Conservative treatment is performed in cases of small $\mathrm{EH}$, isolated hematoma (less than $1 \mathrm{~cm}$ thick and less than $4 \mathrm{~cm}$ along the anteroposterior plane), with no neurological deterioration [42].

Conservative treatment is recommended for the rare presence of intracranial hypertension [24]. Percutaneous EH aspiration is widely used [22,29], as it is a safer alternative to craniotomy, especially when there is a bone fracture [45], the success of the technique being associated with the communication of $\mathrm{EH}$ to cephalohematoma [1]. The aspiration of a recent hematoma can cause new bleeding, and it is strictly necessary to perform the technique in a sterile way for the non-development of cranial osteomyelitis, meningitis and septic shock, due to the introduction of infection during the procedure [24].

Lesions larger than $3 \mathrm{~cm}$, with deviation from the midline [42], neurological deficits or compression of the adjacent brain parenchyma [45], uncontrollable seizures, progressive neurological deterioration and insufficient response to conservative treatment require surgical intervention to drain the hematoma [19]. Yu et al [41] suggest that early surgical treatment can prevent neurological deterioration and ossification of $\mathrm{EH}$, especially in bulky cases and with mass effect. The main indications for craniotomy are thickness of the brain mantle, increased head circumference in subsequent neurological exams, bulging anterior fontanelle and possible cranial sinking or associated hydrocephalus $[2,8,14]$. Osteoplastic craniotomy is the most commonly used surgical technique associated with drainage of the hematoma and hemostasis of the lacerated vessel.

\section{Discussion}

The frequency of the presence of $\mathrm{EH}$ in neonates represents $2 \%$ of all intracranial hemorrhages [1]. The delivery model is a risk factor for neonatal $\mathrm{EH}$, such as the use of forceps and vacuum extraction [12]. Thus, the in-hospital environment proved to be recurrent in the analysis of case reports due to obstetric traumas and those generated in postpartum care with the newborn, a fact that corroborates the case described here.
Thus, the rapid recognition of the disease by the medical team based on the analysis of the clinical condition, which can be masked by the patient's anatomy and pathophysiology, and its evolution by the semiological findings leads to the clinical diagnosis and its confirmation by exams. image [8.43]. The low frequency of occurrence of $\mathrm{EH}$ in neonates is related to the intracranial anatomy of this population, related to the middle meningeal artery not adhering to the skull [29], as occurs in older pediatric patients.

Expansion of studies on the effectiveness of the other tests cited other than the gold standard is clearly necessary. Finally, the low incidence of cases in the literature, highlighted by the long bibliographic time frame necessary to establish an adequate method for the review, results in the lack of a protocol for therapeutic procedures, however the history of the pathology has become a guide for treatment for pediatricians, obstetricians and neurosurgeons.

\section{Conclusion}

The knowledge of neurosurgeons, obstetricians and pediatricians about the occurrence of $\mathrm{EH}$ in newborn is extremely important. Because, the rapid identification and management of the case is important, since the newborn presents rapid recovery with the absence of neurological sequelae, and efficient treatment significantly reduces the rates of morbidity and mortality.

There must be insistence on prophylaxis of $\mathrm{EH}$ in this population, making mothers aware of the care for the newborn on their lap, bed and use of toys inappropriate for their age, as well as the non-practice of mistreatment against the newborn. And for obstetricians, it is necessary to reduce the use of forceps or vacuum extraction during labor.

\section{Disclosure Statement}

The authors have no conflicts of interest to declare.

\section{Funding statement}

None.

\section{References}

1. Vachharajani A, Mathur A. Ultrasound-guided needle aspiration of cranial epidural hematoma in a neonate: Treating a rare complication of vacuum extraction. Am J Perinatol. 2002;19(8):401-4. DOI: 10.1055/s-2002-36837

2. Akiyama Y, Moritake K, Maruyama N, Takamura M, Yamasaki T: Acute epidural hematoma related to cesarean section in a neonate with Chiari II malformation. Childs Nerv Syst. 2001;17:290-3. DOI: 10.1007/s003810000408

3. Braga FM, Ferraz FAP, Campos R. Hematoma extradural em recém-nascido: Relato de caso. Relato de caso. Arq Bras Neurocirurg. 1985;4(1):41-5. 
4. Campbell JB, Cohen J. Epidural hemorrhage and the skull of children. Surg Gynecol Obstet. 1951;92(3):257-80.

5. Chung SW, Park SH, Hwang SK. Neonatal cephalohematoma and epidural hematoma by birth trauma. J Korean Neurosurg Soc. 2006;39(6):464-6.

6. Cooper NA, Lynch MA. Delayed hemorrhagic disease of the newborn with extradural hematomas. $\mathrm{Br}$ Med $\mathrm{J}$. 1979;1(6157):164-5. DOI: 10.1136/bmj.1.6157.164

7. Gouyon JB, Cinquini AM, Sautreaux JL, Thierry A, Giroud M, Alison M. L'hématome extra-dural du nouveau-né. Complication rare d'un accouchement par forceps. Arch Fr Pediatr. 1985;42:333-4.

8. Heyman R, Heckly A, Magagi J, Pladys P, Hamlat A. Intracranial epidural hematoma in newborn infants: Clinical study of 15 cases. Neurosurgery. 2005;57:924-9.

9. King SJ, Boothroyd AE. Cranial trauma following birth in term infants. Br J Radiol. 1998;71(842):233-8. DOI: 10.1259/bjr.71.842.9579191

10. Merry GS, Stuart G. Extradural hematoma in the neonate. Case report. J Neurosurg. 1979;51(5):713-4. DOI: 10.3171/jns.1979.51.5.0713

11. Takagi T, Nagai R, Wakabayashi S, Mizawa I, Hayashi $\mathrm{K}$. Extradural hemorrhage in the newborn as a result of birth trauma. Childs Brain. 1978;4(5):306-18. DOI: 10.1159/000119858

12. Yamamoto T, Enomoto T, Nose T. Epidural hematoma associated with cephalohematoma in a neonate - case report. Neurol Med Chir (Tokyo). 1995;35(10):749-52. DOI: 10.2176/nmc.35.749

13. Lam A, Cruz G, Johnson I. Extradural hematoma in neonates. J Ultrasound Med. 1991;10(4):205-9. DOI: 10.7863/jum.1991.10.4.205

14. Gama CH, Fenichel GM. Epidural hematoma in neonate due to birth trauma. Pediatr Neurol. 1985;1(1):52-3. DOI: 10.1016/0887-8994(85)90010-4

15. Leggate JR, Lopez-Ramos N, Genitori L, Lena G, Choux M. Extradural hematoma in infants. Br J Neurosurg. 1989;3(5):533-9. DOI: 10.3109/0268869890900284

16. Okuno T, Miyamoto M, Itakura T, Ueno M, Shimizu M, Minamide A, Komai N. A case of epidural hematoma caused by vacuum extraction without any skull fractures and accompanied cephalohematoma. No Shinkei Geka. 1993;21(12):1137-41.

17. Pereira CU, Choux M, Genitori L, Lena G, Cavalheiro S. Hematoma extradural no primeiro ano de vida. Paper presented at: IV Congresso Brasileiro da Academia Brasileira de Neurocirurgia; November 19th to 24th, 1991; Guarujá, São Paulo.

18. Pereira CU, Genitori L. Hematoma extradural no recémnascido. Pediatria Moderna XXIX: São Paulo. 1993;253-5.

19. Sharma AK, Diyora BD, Shah SG, Pandey AK, Mamidanna R. An extradural and subdural hematoma in a neonate. Indian Journal of Pediatrics. 2005;72(3):e40-2.

20. Harpold TL, McComb JG, Levy ML. Neonatal neurosurgical trauma. Neurosurg Clin N Am. 1998;9:141-54. 21. Sato R. Occult large epidural hemorrhage in a newborn infant after in-hospital fall. J Neonatal Perinatal Med. 2018;11(2):195-7. DOI: 10.3233/NPM-181752

22. Aoki N. Epidural hematoma in the newborn infants: Therapeutic consequences from the correlation between haematoma content and computed tomography features. Acta neurochir (Wien). 1990;106:65-7. DOI: 10.1007/BF01809334 23. Josephsen JB, Kemp J, Elbabaa SK, Al-Hosni M. LifeThreatening neonatal epidural hematoma caused by precipitous vaginal delivery. Am J Case Rep. 2015;16:50-2. DOI: $10.12659 / A J C R .892506$
24. Smets K, Vanhauwaert D. Treatment of cranial epidural hematoma in a neonate by needle aspiration of a communicating cephalohematoma. Eur J Pediatr. 2010;169:617-9. DOI: 10.1007/s00431-009-1071-4

25. Coats B, Margules SS. Potential for head injuries in infants from low-height falls. J Neurosurg Pediatrics. 2008;2:321-330. DOI: doi.org/10.3171/PED.2008.2.11.321

26. Pollina J, Dias MS, Kachurek D, Arbesman M. Cranial birth injuries in term newborn infants. Pediatr Neurosurg. 2001;35(3):113-9. DOI: 10.1159/000050403

27. Gregorio-Hernández R, González-Valcarcel $\mathrm{M}$, Escobar-Izquierdo AB, López-Lozano Y, Cabada-Del-Río A. Neonatal epidural haematoma. Presentation of 3 cases and a literature review Anales de Pediatría (English Edition). 2018;88(1):50-1. DOI: 10.1016/j.anpedi.2017.01.004

28. Chang JH, Choi JY, Chang JW, Park YG, Kim TS, Chung SS. Chronic epidural hematoma with rapid ossification. Childs Nerv Syst. 2002;18(12):712-6. DOI: 10.1007/s00381002-0664-2

29. Negishi H, Lee Y, Itoh K, Suzuki J, Nishino M, Takada S, Yamasaki S. Nonsurgical management of epidural hematoma in neonates. Pediatr Neurol. 1989;5(4):253-6. DOI: 10.1016/0887-8994(89)90086-6

30. Arkins TJ, McLennan JE, Winston KR, Strand RD, Suzuki Y. Acute posterior fossa epidural hematomas in children. Am J Dis Child. 1977;131(6):690-2. DOI: 10.1001/archpedi.1977.02120190084019

31. Esparza J, Portilho JN, Mateos F, Lamas E. Extradural hemorrhage in the posterior fossa in neonate. Surg Neurol. 1982;17(5):341-3. DOI: 10.1016/0090-3019(82)90305-6

32. Motte J, Dulac D, Rousseaux P, Morville P. L'hématome extra-dural chez l'enfant de moins d'un an. Arch Fr Pédiatr. 1985;42:301-3.

33. Hamlat A, Heckly A, Adn M, Poulain P. Pathophysiology of intracranial epidural haematoma following birth. Med Hypotheses. 2006;66(2):371-4. DOI: 10.1016/j.mehy.2005.08.045

34. Scheibl A, Calderon E, Borau M, Prieto R, Gonzalez F, Galiana G. Epidural hematoma. J J Pediatr Surg. 2012;47:E1921. DOI: $10.1016 /$ j.jpedsurg.2011.10.078

35. Villarejo F, Belinchón JM, Carceller F, Gómez-Sieraa A, Pascual A, Cordobés F, Pérez-Diaz C, Rivero B. Lesiones craneales secundarias a parto asistido con forceps. Neurocirugia (Astur). 2009;20(3):262-4.

36. Choux M, Grisoli F, Peragut J. Extradural hematomas in children. 104 cases. Childs Brain. 1975;1(6):337-47. DOI: $10.1159 / 000119585$

37. Mazza C, Pasqualin A, Feriotti G, Da Pian R. Traumatic extradural haematomas in children: experience with 62 cases. Acta Neurochir (Wien). 1982;65:67-80.

38. Erdogan B, Sen O, Bal N, Cekinmez M, Altinors N. Rapidly calcifying and ossification epidural hematoma. Pediatr Neurosurg 2003; 39(4):208-11. DOI: $10.1159 / 000072473$

39. Kotil K, Akçetin MA. Asymptomatic chronic ossified epidural hematoma in a child: a rare entity. Ulus Travma Acil Cerrahi Derg. 2006;12(2):164-6.

40. Park SH, Hwang SK. Surgical treatment of subacute epidural hematoma caused by a vacuum extraction with skull fracture and cephalohematoma in a neonate. Pediatr Neurosurg. 2006;42(4):270-2. DOI: 10.1159/000092369 41. Yu DK, Heo DH, Cho SM, Cho YJ. Rapidly calcified epidural hematoma in a neonate. J Korean Neurosurg. 2008;44(2):98-100. DOI: 10.3340/jkns.2008.44.2.98

42. Bruce DA. Pediatric head injury. In: Wilkins RH, Rengachary SS, eds. Neurosurgery $2^{\text {nd }}$ ed. Mcgraw-Hill; 1996:2709-10. 
43. Dohrmann GJ, Rubin JM. Intraoperative ultrasound in neurotraumatology; brain, spinal cord and cauda equine. In: Harris P, eds. Thoracic and Lumbar Spine and Spinal Cord Injuries. Advances in Neurotraumatology, vol. 2. New York: Springer-Verlag; 1986:51-64.

44. Aoki N. Epidural hematoma communicating with cephalohematoma in a neonate. Neurosurgery. 1983;13(1):557. DOI: 10.1227/00006123-198307000-00011
45. Nogushi M, Inamasu J, Kawai F, Kato E, Kuramae T, Oyanagi T, Takahashi T, Ihara M. Ultrasound-guided needle aspiration of epidural hematoma in a neonate after vacuum Assisted delivery. Childs Nerv Syst. 2010;26(5):713-6. DOI: 10.1007/s00381-009-1072-7 
